\title{
Basic properties of methyl plamitate-diesel blends
}

\begin{abstract}
This study characterized the properties of methyl palmitate-diesel blended fuels at specified volumetric proportions. The physicochemical properties of the blended fuels (B10, B20, B30, B40, and B50) were measured and compared with those of the ASTM D7467 standard. Differential scanning calorimetry was employed to monitor the crystallization characteristics of the tested fuels under low temperature conditions. Results showed that the properties of the blended fuels conformed to the standard ASTM D7464. The blended fuel with $30 \%$ methyl palmitate maintained its cold filter plugging point of $-1.33{ }^{\circ} \mathrm{C}$ to $9.33{ }^{\circ} \mathrm{C}$. The oxidation stability, density, gross heating value, flash point, and kinematic viscosity of the fuels were also examined. A fuel containing $30 \%$ methyl palmitate is recommended for engine operations in temperate regions.
\end{abstract}

Keyword: Methyl palmitate; Cold flow properties; Physicochemical properties; Blended fuels 